\title{
The impact of the environmental crisis on the purchasing power of consumers
}

\author{
Askar Smagulov ${ }^{1}$, Yerzhan Zhatkanbaev ${ }^{1}$, Jumabek Tumbai ${ }^{1}$, Shynar Abdikul ${ }^{1 *}$, Kymbat \\ Muratbekova ${ }^{1}$, Asylbek Agymbay ${ }^{1}$ \\ ${ }^{1}$ al-Farabi Kazakh National University, 71 al-Farabi Ave., 050040, Republic of Kazakhstan.
}

\begin{abstract}
The subject of the article is purpose of consumer behavior and its direct connection and interaction with ecological situation in the world. Several examples show that consumption which exceeds the normal level is determined by irrational goals and motives. These motives have essentially the nature of public ritual. They are supported by the social imitation instinct rather than by conscious individual goal setting. The irrationality and arbitrariness of consumption purposes therefore means also the irrationality of the goals and meaning of the production. The conclusion is that an economic system which is based on another alternative ultimate goals and meanings may be more effective in the face of a growing environmental crisis.
\end{abstract}

\section{Introduction}

The actions that people make and the choices they make for the consumption of certain products and services have a direct and indirect impact on the environment, as well as on personal and collective well-being. Major environmental and social problems have arisen due to the rapid developmental activities undertaken by humans, especially since the industrialization era. On the one hand, such activities (irresponsible industrial practices) have been held responsible for global warming, depletion of natural resources and other environmental problems, and on the other, they have led to the creation of economic inequality among the various segments of society. The work considers the problem of formation of ecological consciousness of the person, as a factor affecting the change of the state of ecological situation in the whole world. Consumption is a total idealistic practice that has little to do with actual satisfaction of needs or with the principle of reality; "Moderate" consumption does not happen. A consumer society is where not only the desire to buy is cultivated, but where consumption itself is a meta-need, which underlies the whole system of fictitious needs created by the world of advertising and mass media. The essence of consumption is not in the ability to purchase the advertised product, but in the desire to do

\footnotetext{
${ }^{*}$ Corresponding author: shinar1994@mail.ru
} 
so; consumption is not localized in the pocket, but in the sphere of desire. Consumer society is a set of relations where the symbolism of material objects, which acts as the meaning of life, dominates, enticing consumers to acquire things and thereby give themselves a certain status.

Sustainable consumption can be defined as "consumption that simultaneously optimizes the environmental, social, and economic consequences of acquisition, use and disposition in order to meet the needs of both current and future generations"

\subsection{The conscious retail model within the fashion marketplace}

Until the twentieth century, fashion was "slow": dresses and costumes were sewn by tailors only after ordering, fabrics were expensive. However, with the appearance of factory production(industrialization) and finished dress stores, the opposite problem arose overproduction. Now, any resident of developed countries can go to the store and buy a cheap jacket made of polyester, which, perhaps, will be worn only once. This is phenomena calls"fast fashion", due to which random purchases are accumulated, and then thrown away due to uselessness. According to statistics, in Hong Kong alone, 1,400 T-shirts are thrown out every minute and for this reason, fashion and clothing industry ranks second in the world in terms of sweepings.

At the same time, a huge amount of water is spent on the production of clothing. According to Greenpeace, 2,700 liters are spent on production of one T-shirt - this is the amount of water one person consumes on average in 900 days. In the process of staining tissues, many environmentally harmful substances are used. For example, fluorinated compounds (PPS), heavy metals and solvents. All of this components get into the rivers and consequently polluting drinking water. The problem is especially acute for the countries of Southeast Asia, where the vast majority of factories are located.

Manufacturers seek to sell as much as possible, to increase the net profit of the company. Collections in the mass market are replaced several times (2-3) a season. Each time, a new marketing campaign assures that it is precisely these things that cannot be dispensed with. Brands create artificial excitement by limiting collections: "buy it right now, otherwise you won't get these things anymore in your life" and repeat it each season.

Buyers want the quick pleasure that impulsive shopping can bring to them, however short euphoria usually ends with regrets when the acquired good is useless. So there is a feeling of "full closet, but there is nothing to wear." As John Kenneth Galbraith, American economics theorist, author of "The New Industrial Society", noted, in a consumer society, purchases are made under the influence of emotions and also it can be said that, irrationality of customer behavior is connected with marketing manipulations made by producers.

Desire for instant gratification and affordable products encourages many consumers to prefer fast fashion [1], but other consumers identify the fast fashion business model as detrimental to the environment and extremely unethical [2]. Sustainability is arguably the biggest issue in fashion today, evidenced by the growing movement toward retailers at all levels promoting their goods as 'ethical' or 'sustainable' in production, process or human resource. Consumers worldwide are beginning to question fast fashion's dominance and practices, and are less motivated to purchase disposable fashion. There are significant public calls for consumers to reduce their consumption of well-known fast-fashion brands, and for 
the fashion industry, generally, to counter the massive textile waste problem the world is facing.

Slow fashion is a relatively new concept in the apparel industry, and, as such, there is no one concrete definition that positions and frames the movement amongst the foundational areas from which it has evolved (such as sustainability and social responsibility).

\section{Literature Review}

In an effort to describe sustainable consumption, previous studies have focused primarily on the fundamental values, opinions and intentions of consumers when buying eco-friendly goods [3]. Eco-innovation describes the creation of novel and competitively priced goods, processes, systems, services, policies, and procedures that satisfy human needs and improve the quality of life while ensuring sustainable development with minimal use of natural resources and minimal release of toxic substances [4].

Theory of reasoned action (TRA) [5] and the theory of planned behavior (TPB) [6] are the major theoretic frameworks employed by many studies to examine the various forms of ecological behaviors in western countries, including purchasing of sustainable products [7]. Several prior studies have observed that there is a weak association between consumers' purchase behavior and positive attitude towards sustainable purchase practices [8]. Various researchers have highlighted certain limitations of TPB and TRA and proposed various other frameworks to study consumer sustainable behavior. Johnstone and Lindh [9] suggested that applications of TRA and TPB are restricted as TPB doesn't represent oblivious and secondary pathways to axiological change. Also, TPB and TRA do not consider behavioral aspects such as consumer past behavior and habits [10]. Phipps et al. [11] incorporated social cognitive theory (SCT) and recommended a new framework of reciprocal determinism to understand consumer sustainable behavior. Keeping in mind the limitations of TRA and TPB [they do not account for unconscious and various important direct and indirect pathways to axiological change [12]], the conceptual model for the present study incorporates the suggestions (premise) of reciprocal determinism theory into the key constructs of TPB and tries to determine the impact of key psychological variables (personal factors) on consumers' sustainable purchase behavior.

Another reason for social irrationality is the psychology of the crowd, when the rational critical principle of the personality is suppressed by the irrational mass consciousness. The basis of irrational consumer behavior here is the biological mechanisms characteristic of social animals, such as infection, imitation, suggestion. Imitation helps in standard situations, without too much thought, behave the same way are surrounding. Therefore, in the same situation, people from different cultures behave differently. Imitation is one of the main mechanisms of the socialization process and is based on cost savings in training. Therefore, we can say that the imitative person is rational, at least in this. Infection is associated with the individual's perception of the mood of the group and the forms of behavior caused by it. In the consumer market, this is manifested in the fact that consumers (and this reveals the index of consumer sentiment) massively change their moods regarding purchases of different groups of goods, which may be due to rumors, expectations of incomes and prices, just a change in the mood of groups for reasons unknown to the researcher. Suggestion as a source of irrationality is associated with the tendency of consumers to uncritically perceive external information, trusting the opinion of an authoritative person. If an individual enters the crowd as a group of people captured by the same emotions, his rational thinking and ability to conscious actions are suppressed. 
Previous studies on sustainable purchasing have examined various personal, psychological and social factors influencing consumers' ecologically and socially conscious purchasing [13], but none of the studies have explored the spiritual dimension. Lee K [14] introduced perceived marketplace influence as a new construct which needs further examination. Also, other key psychological factors influencing consumer sustainable purchase behavior need to be studied [15].

\section{Methodology}

Materialism has been extensively studied. The literature has described materialism as a cultural/structural or an individual difference variable. In this study, we see materialism as a consumer value and define it as "the importance a person places on possessions and their acquisition as a necessary or desirable form of conduct to reach desired end states" [16]. According to this value oriented schema, possessions play a central role for highly materialistic people; they believe that possessions lead to happiness and life satisfaction, and they use material goods to judge their own success and that of others. Several studies in various disciplines such as psychology, sociology, and marketing took this value-oriented perspective and found that materialism can be a critical individual difference variable to segment markets [17]. They suggested that materialism, as a means to define oneself [18], is useful to better target potential supporters for charitable organizations. Prior research overall indicates that materialism is associated with both negative and positive connotations, which accordingly guides our consumption behaviors [19]. The article examines how consumers experience, are influenced and are influenced by the digital environment they are in as part of their daily lives [20].

Ethical consumption has become a burgeoning social phenomenon. Mainstream consumers increasingly express ethical concerns and care about the impact of their consumption choices on the environment, animals, and society. For instance, $45 \%$ of USA consumers reported that they buy products from companies that they perceive as ethical, and more than one-third (35\%) of Americans said that they stop buying from brands that they perceive as unethical even if there is no substitute available, according to Mintel research (2015). Ethical considerations are increasingly affecting consumer purchase decisions, and the growth of ethical culture has induced more companies to engage in socially responsible behaviors and to implement ethical attributes in their products and services [21]. However, several studies on ethical consumption have indicated that consumers' ethical attitudes do not properly mirror their shopping [22]. For instance, when it comes to decision making, over $85 \%$ of consumers choose not to learn about a product's ethical attributes (e.g., use of child labor) even if many do care to learn about other attributes such as style and wash of jeans [23]. Although the gap between expressed attitude and behavior is widely acknowledged in

many fields [24], this inconsistency tends to be exacerbated when the focus is on a socially desirable behavior such as ethical consumption [25].

Ethicality and materialism cannot be separately understood in modern society. Although materialism is prevalent now days, consumers are also becoming more socially conscious and ethically concerned. They care about how their purchase impacts people, animals, and the earth. They are willing to demonstrate social and environmental responsibility (e.g., fairtrade coffee, energy-saving light bulbs) in their buying behavior.

As example of connection between materialism and ethical consumption, we took a statistics of consumption of goods and services among different sectors in the Republic of Kazakhstan. 


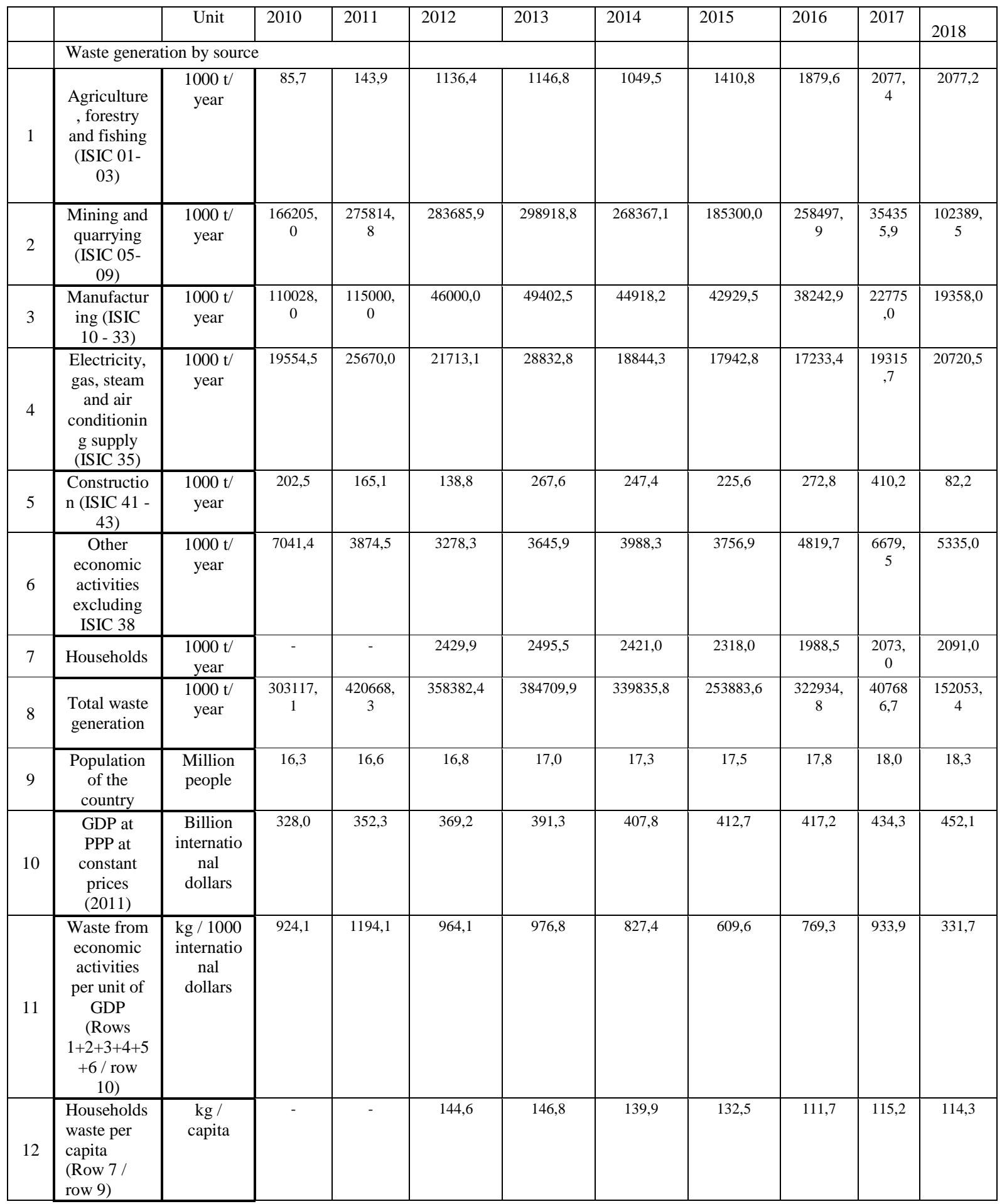

Notes: The source of information is the Ministry of ecology, Geology and natural resources of the Republic of Kazakhstan. Information is provided on hazardous waste by type of 
economic activity, the classification of waste is given in accordance with the Basel Convention. For households, information is generated by the statistics Committee.

Considering the data of the selected statistics, it can be noted that the level of waste increased in proportion to population growth and an increase in GDP in the period from 2010 to 2018.

Therefore, the amount of waste polluting the environment directly depends on the number of people living in Kazakhstan and the rate of economic development, i.e. the emergence of new niches for businesses, building new manufacturing companies and development of small and medium sized businesses, which will increase the level of unconscious consumption.

Considering all the above information, we can make a SWOT analysis of sustainable development, which directly depends on the environmental situation in the country.

\begin{tabular}{|c|c|}
\hline Strengths & Weaknesses \\
\hline $\begin{array}{l}\text { 1.Strengths lie in the valuable and significant } \\
\text { resources in the country, their species diversity } \\
\text { and experience in use. (Natural Resources). } \\
\text { 2. Location of the country. } \\
\text { 3.A variety of mineral resources for the } \\
\text { successful development of its own industry. } \\
\text { 4. Wildlife resources. }\end{array}$ & $\begin{array}{l}\text { 1.Low level of funding for environmental and } \\
\text { related activities. } \\
\text { 2. Lack of a convenient waste management } \\
\text { system. } \\
\text { 3.Lack of environmental education and low } \\
\text { level of empathy of citizens. } \\
\text { 4. Low degree of social responsibility of } \\
\text { companies. } \\
\text { 5.Large impact of advertising and marketing on } \\
\text { consumption. }\end{array}$ \\
\hline Opportunities & Threats \\
\hline $\begin{array}{l}\text { 1.High demand for modernization. } \\
\text { 2.Potential in the use of natural resources in } \\
\text { industrial and agricultural sectors while using } \\
\text { innovative methods that reduce waste. } \\
\text { 3. Organization and management of rational use } \\
\text { of natural resources and environmental } \\
\text { protection. } \\
\text { 4. The introduction of new training methods to } \\
\text { improve education in the field of ecology and } \\
\text { waste management. } \\
\text { 5.Environmental investments. } \\
\text { 6.Introduction of values such as environmental } \\
\text { responsibility into the organizational culture of } \\
\text { companies. }\end{array}$ & $\begin{array}{l}\text { 1.Neglecting environmental factors in the } \\
\text { construction of new enterprises or factories of } \\
\text { industrial activity. } \\
\text { 2. Increased consumption of scarce natural } \\
\text { resources. } \\
\text { 3. Aggravation of raw materials, fuel, energy, } \\
\text { water and environmental problems. } \\
\text { 4. Extinction of certain animal species due to } \\
\text { excessive consumption of microplastic. } \\
\text { 5. Deterioration of the human immune system } \\
\text { due to the consumption of excessive amounts of } \\
\text { microplastic. }\end{array}$ \\
\hline
\end{tabular}

Sustainable purchasing is important and many studies have highlighted the need to foster and examine sustainable purchase behavior [26]. In recent times, production of sustainable goods such as biodegradable products, energy efficient appliances, etc. has increased, but associated benefits have been outpaced by the increase in consumption.

\section{Results and Discussion}

The current study examines the impact of key psychological variables on young consumers' sustainable purchase behavior. Drive for environmental responsibility has the highest impact on consumer sustainable purchase behavior. Kumar and Ghodeswar [27] have had similar 
observations where drive for environmental responsibility encouraged green purchase behavior and consumers' green purchase decisions were formed on the basis of ecological, individual, and social outcomes. Consumers' choice of purchase is associated with their satisfaction of utilitarian, emotional and experiential necessities; fulfilment of such utilitarian, emotional and experiential necessities are key to green product purchases also. Further, strong positive influence of perceived consumer effectiveness on consumers' sustainable purchase behavior complements the social dilemma theory which advocates that perceived efficacy, or the degree to which one trusts that one can have any kind of effect towards accomplishing an objective, impacts cooperation or green practices [28,29].

\section{Conclusions}

The current study adds to extant research by observing the impact of key psychological variables on consumers' sustainable purchasing behavior. Results of the study reveal that the key predictors of consumers' sustainable purchase behavior are drive for environmental responsibility followed by spirituality and perceived consumer effectiveness. Results are supported by past studies [30]. For advertisers and sustainable producers, the results obtained are very useful as these would help in designing strategies to promote sustainable purchasing. A vast majority of involved people are of the view that sustainable purchase behavior should be a mindset of society, and not merely a 'marketable' or 'advertisable' concept. In other words, citizens must voluntarily engage in activities that protect the environment and have an inherent sense of responsibility towards the environment while producing and consuming. Lasting changes would occur only if sustainable consumption became a spontaneous thought process, and sustainable consumption behavior, voluntary. Emphasis on key psychological factors determined by the present study can shape the mindset of the consumers and direct them towards sustainable purchasing. There are certain limitations to this study. In the current research, self-reported data are taken into consideration which may have a social desirability bias. To address this issue, scale items were adopted from various sources, and it could be outdated, because of fast pace of change in the world. Available literature indicates that the number of eco-friendly consumers is growing swiftly, but the degree of acceptance of sustainable products among them. With the passage of time, more people have shown the willingness to take up sustainable consumption habits; however, this willingness has not been reflected in their purchasing behavior.

\section{References}

1. V. Bhardwaj, A. Fairhurst, Retail Distrib. Consum. Res. 20 (1), 165-173 (2010)

2. L. Siegle, Why Fast Fashion is Slow Death for the Planet. The Guardian Viewed 7 February from https://www.theguardian.com/lifeandstyle/2011/may/08/ fast-fashion-deathfor-planet, (2018).

3. G. Liobikienė, Š.Grincevičienè, J. Bernatonienè, J. Clean, Environmentally friendly behaviour and green purchase in Austria and Lithuania. Prod. (142) 3789-3797, (63)143151 (2017).

4. G. Mutanov, S. Ziyadin, A. A.Shaikh, Enterpreneurship and Sustainability Issues, 6 (4) (2019).

5. I. Ajzen, M. Fishbein, Understanding Attitudes and Predicting Social Behaviour. PrenticeHall, Englewood Cliffs, (NJ, 1980). 
6. I. Ajzen, From intentions to actions: a theory of planned behavior. In: Action Control. Springer, Berlin Heidelberg, 11-39 (1985).

7. G. Liobikienė, J. Mandravickaite, J. Bernatonienè, Theory of planned behavior approach to understand the green purchasing behavior in the EU: a cross-cultural study. (125) 3846, (2016).

8. S.C. Tseng, S. W. Hung, J. Clean, A framework identifying the gaps between customers' expectations and their perceptions in green products. 59 (174-184), (2013).

9. L. Johnstone, C. Lindh, J. Consum. Behav, The sustainability-age dilemma: a theory of (un) planned behaviour via influencers. 17 (1), 127-139 (2018).

10. R. Nittala, Green consumer behavior of the educated segment in India. J. Int. Consum. Mark. 26 (2) 138-152, (2014).

11. M. Phipps, L. K. Ozanne, M. G. Luchs, S. Subrahmanyan, S. Kapitan, J. R. Catlin, T.Weaver, J. Bus, Understanding the inherent complexity of sustainable consumption: a social cognitive framework. Res. 66 (8), 1227-1234, (2013).

12. L. Johnstone, C. Lindh, J. Consum, The sustainability-age dilemma: a theory of (un) planned behaviour via influencers. 17 (1), 127-139 (2018).

13. M. M. Mostafa, Gender differences in Egyptian consumers' green purchase behaviour: the effects of environmental knowledge, concern and attitude. 31 (3), 220-229 (2007).

14. K. Lee, Making environmental communications meaningful to female adolescents: a study in Hong Kong. Sci. Commun. 30 (2), 147-176 (2008).

15. K. Lee, The green purchase behavior of Hong Kong young consumers: the role of peer influence, local environmental involvement, and concrete environmental knowledge, (2010).

16. M. Richins, S. A. Journal of Consumer Research, (19) 303-316 (1992).

17. M. Cleveland, W. Chang, Journal of Business Research, 62(10), 963-971 (2009).

18. L. J. Shrum, N. Wong, F. Arif, S. K. Chugani, A. Gunz, T. M. Lowrey, K.Scott, Journal of Business Research, 66(8), 1179-1185 (2013).

19. R. Belk, Journal of Consumer Research, 12 (265-280) (1985).

20. S. Ziyadin et al. The role of social media marketing in consumer behaviour //E3S Web of Conferences. (2019). DOI: 10.1051/e3sconf/201913504022

21. T. Newholm, D. Shaw, Journal of Consumer Behaviour: An International Research Review, 6(5) 253-270 (2007).

22. L. Atkinson, Y.Kim, "I drink it anyway and I know I shouldn't": Understanding green consumers' positive evaluations of norm-violating non-green products and misleading green advertising. Environmental Communication, 9(1) 37-57 (2015).

23. D. M. Zane, J. R. Irwin, R. W. Reczek, Journal of Consumer Psychology, 26(3), 337349 (2016).

24. R.Belk, Journal of Consumer Research, (12) 265-280 (1985). 
25. P. Ulrich, C. Sarasin, (Eds.). Facing public interest: The ethical challenge to business policy and corporate communications (Vol. 8). Springer Science \& Business Media, (2012).

26. B. Kumar, A. K. Manrai, L. A. Manrai, J. Retail. Consum. Serv, Purchasing behaviour for environmentally sustainable products: a conceptual framework and empirical study. $\mathbf{3 4}$ (1-9), (2017).

27. Akhmetshin, E. M., Vasilev, V. L., Bakhvalov, S. I., Prikhod'ko, A. N., \& Kazakov, A. V. (2017). International Journal of Economic Research, 14(15), 409-416.

28. P. A. M. Van Lange, W. B. G. Liebrand, D. M. Messick, H.A.M. Wilke, Social dilemmas: the state of the art-introduction and literature review, (1992).

29. Mutanov, G., Ziyadin, S. /E3S Web of Conferences, DOI: $10.1051 / \mathrm{e} 3$ sconf/201913504056 (2019)

30. P. Kumar, B. M. Ghodeswar, Factors affecting consumers' green product purchase decisions. Mark. Intell. Plan. 33 (3), 330-347 (2015). 